\title{
Managing conflicts in water resources allocation: the case of Urumia Lake Basin, Iran
}

\author{
S. Oloumi Zad ${ }^{1}$, W. Ravesteijn ${ }^{1}$, L. Hermans ${ }^{2}$ \& E. van Beek ${ }^{3}$ \\ ${ }^{1}$ Section of Technology Dynamics \& Sustainable Development, \\ Delft University of Technology, The Netherlands \\ ${ }^{2}$ Section of Policy Analysis, Delft University of Technology, \\ The Netherlands \\ ${ }^{3}$ Department of Water Engineering \& Management, University of Twente, \\ The Netherlands
}

\begin{abstract}
Lake Urumia is a salt lake located in the northwest of Iran. During the past 14 years, increased water demand and droughts have led to severe environmental degradation combined with a drop of about $5 \mathrm{~m}$ in the lake's water level. This paper presents the results of a case study carried out to contribute to the development of a roadmap aimed at reaching a sustainable water allocation in the basin. A combination of the Large Technological System approach and the Graph model for conflict resolution is used to provide a clear picture of the basin and the stakeholders involved, including their activities, and to study their behaviour in order to identify strategies for achieving a sustainable outcome.

Keywords: socio-technical systems, Graph model for conflict resolution, stakeholder involvement, sustainable water resources allocation, Lake Urumia.
\end{abstract}

\section{Introduction}

The need for water allocation is growing because of an increase in water demand, on the one hand, and a decrease in water availability, on the other hand. As a consequence, managing conflicts among stakeholders, who have different interests and participate in the process of water allocation, becomes important. So, the question is how to increase the collaboration of stakeholders or influence their preferences to achieve a suitable outcome. This paper deals with this question in the case of the Urumia Lake Basin (Iran), which faces ecological, 
social, and economic problems due to a fall in the lake's water level. It provides a clear problem analysis through the application of the Large Technical System approach. Moreover, the Graph model for conflict resolution is used to analyse the behaviour of the stakeholders involved in the process of water allocation. It aims to determine the possible outcomes of the process and develop strategies, if necessary, for achieving a more sustainable outcome. The usefulness of this method for this case has been verified by its application to two previous negotiation processes: the development of an integrated water management plan for the basin and allocating its water between stakeholders for a normal year.

The main sources of data for this case study are provided by previous researches, including the work of Yekom Consulting Engineers [1, 2], Pandam Consulting Engineers [3], Water \& Wastewater Macro Planning Bureau [4], a dissertation by Nazaridoust [5], a dissertation by Hashemi [6], and the Conservation of Iranian Wetlands Project [7, 8]. Besides that, twenty interviews and two field visits provided case information [9].

\section{The large technological system approach}

It has been argued that applying the Large Technical Systems (LTS) approach can have a significant contribution to clarifying the challenges of the various actors or stakeholders in hydraulic system building [10]. The roots of the LTS or "socio-technical systems" approach can be found in the book "Networks of power" by Thomas Hughes [11]. He introduced a system perspective for studying infrastructural technologies. Before that, historical and sociological technology studies mainly focused on individual inventors and/or isolated technical applications [11]. A LTS is defined as a network of "system builders" and "system components" working together like the parts of a single huge machine. Components of such a technological system are physical or nonphysical artefacts which function as a part of that system; they also include actors [12, 13]. Each component interacts, directly or indirectly, with other components in the system. Therefore, if the characteristics of a component change or the component will be removed from the system, this will influence the characteristics of other components. Furthermore, such a technological system has an environment consisting of intractable factors that are not under control of the system builders $[12,14]$.

\section{The graph model for conflict resolution}

A strategic conflict refers to the interaction between two or more decision makers who are independent of each other. They make choices that determine the final state of the process and each of them has a preference over the final state $[15,16]$. The Graph model for conflict resolution was developed by Fang et al. [17] as a decision support technique for such conflicts. It consists of two phases: modelling and analysing.

Three terms have been used for modelling a conflict: decision makers, options and preferences. Decision-makers are the key actors, stakeholders, participants 
and players in a conflict situation. Options refer to the actions that a decision maker can or cannot take in a conflict. A strategy is the option that a decision maker selects. A combination of strategies results in a state, sometimes also referred to as outcome or scenario. Some of these states are infeasible as they cannot take place in a real conflict. The infeasible states are ignored and removed from the model. Preferences of each decision maker over the feasible states should be determined [17-19].

In the analysis part, the possible interactions among decision makers will be studied with the use of a "stability analysis". In this stage, all the possible unilateral movement of decision makers to a more preferred state will be investigated to predict what can happen. A unilateral movement occurs when a decision maker changes his/her strategy to achieve a more preferred state. The result is a stable state for that particular decision maker. It means that there is no advantage for that decision maker to take a unilaterally movement toward another state. A range of solution concepts are used to calculate the stability of states. Equilibrium is the state that is stable for all the decision makers $[15,17]$.

\section{The lake and its problems}

Lake Urumia is a hyper saline lake between the provinces of East Azerbaijan and West Azerbaijan in the northwest of Iran. However, the basin includes the province of Kurdistan as well. Figure 1 shows the location of the lake indicating the borders of the provinces.

Considering the Urumia Lake Basin as a system, four groups of components and two categories of environment can be formed (see Figure 2). What follows is a short description and analysis of the problem on the basis of the system diagram in Figure 2. The lake including its islands has been designated as a National Park since 1975 for its unique natural and ecological features [20-22]. The lake and its wetlands have several important characteristics. Firstly, they trap and store sediments, nutrients and pollutants from river inflows and prevent them from spreading into the wider environment. Secondly, they contribute to regulating temperature and humidity of the surrounding area, thereby making it suitable for agriculture. Thirdly, the wetlands recharge the aquifers and prevent saltwater intrusion from the lake into those aquifers. Finally, the beautiful landscape of the lake can be considered as one of the main attractions of the adjoining provinces for tourism [7, 8, 20].

Unfortunately, the lake's water level started falling due to a severe drought during 1999-2001 and its decline has continued since then. The water level dropped to more than $4 \mathrm{~m}$ below its long term annual average in 2009. Besides the ecological degradation, there are other concerns. For example, parts of the lake have dried up and if this continues, wind will disperse the salt particles, which is a potential threat to human health. Furthermore, the climate of the area will become less suitable for agriculture as the lake and its wetlands can no longer support it [8, 9, 24].

Drought and increase in water use as a result of population growth and execution of national development plans in the region are identified as the main 
reasons. The national development plans are the national policies and strategies defined in a five year plan. They started since 1989, after the Iraq-Iran war [9, 21].

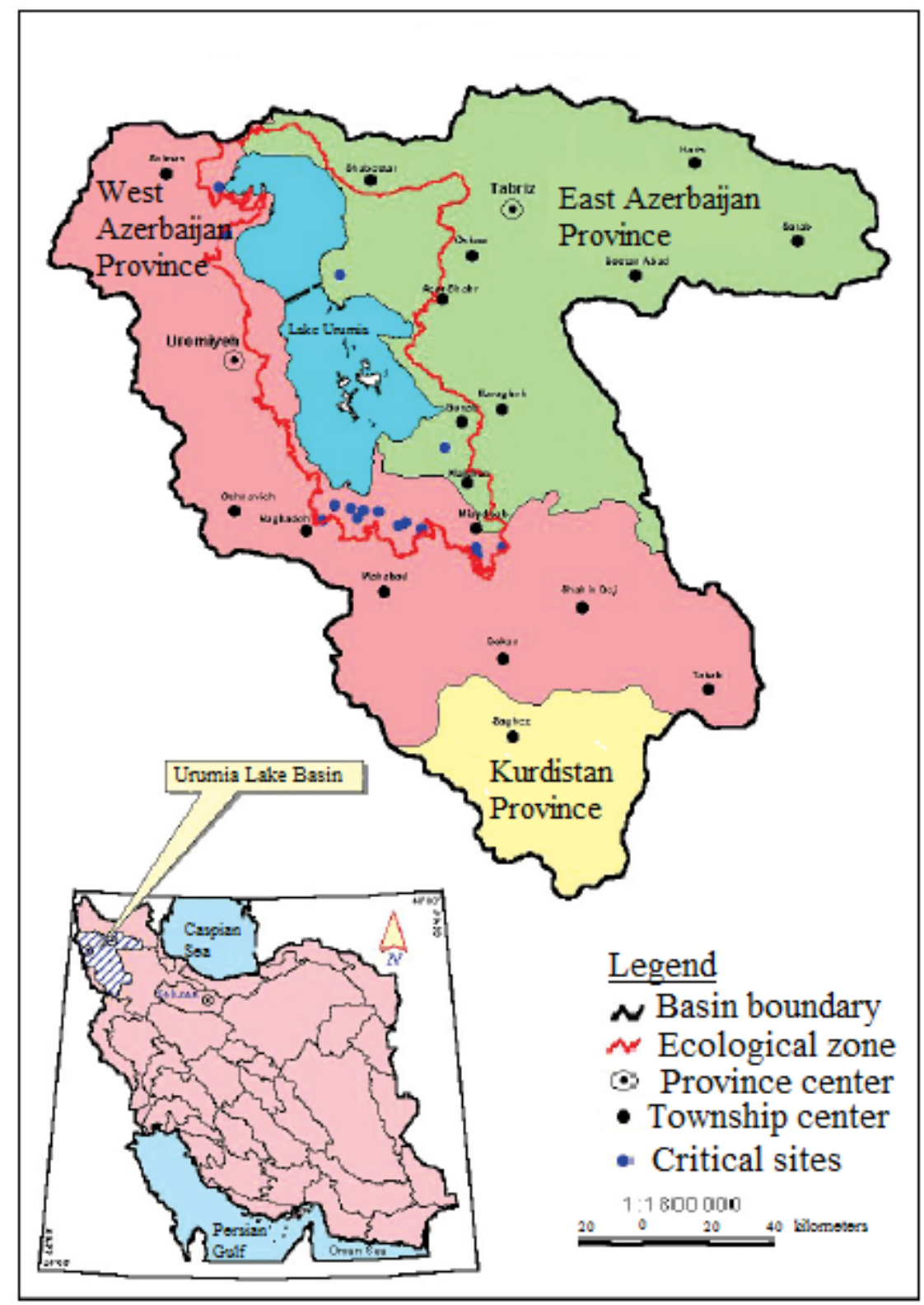

Figure 1: $\quad$ Urumia Lake Basin with the borders of the provinces [8]. 
The first development plan aimed at reconstruction and economic growth with the emphasis on increasing self-sufficiency through strategic crops. Because of a good potential for farming in the Urumia Lake Basin governmental support led to comprehensive developments in the region, especially in the agricultural sector. Thus, West Azerbaijan has become one of the main centres for agriculture, Kurdistan for animal husbandry and agriculture, and East Azerbaijan for industry [9, 21]. Environmental issues were part of the main policies in the second development plan. However, both provinces of East and West Azerbaijan gave priority to industry, agriculture and hydro infrastructure over the environment. They believed economic growth and environmental preservation are incompatible. The increase in the lake's water level between 1988 and 1998 was an incentive for the provincial water boards to enhance their investments in water development plans [21, 22].

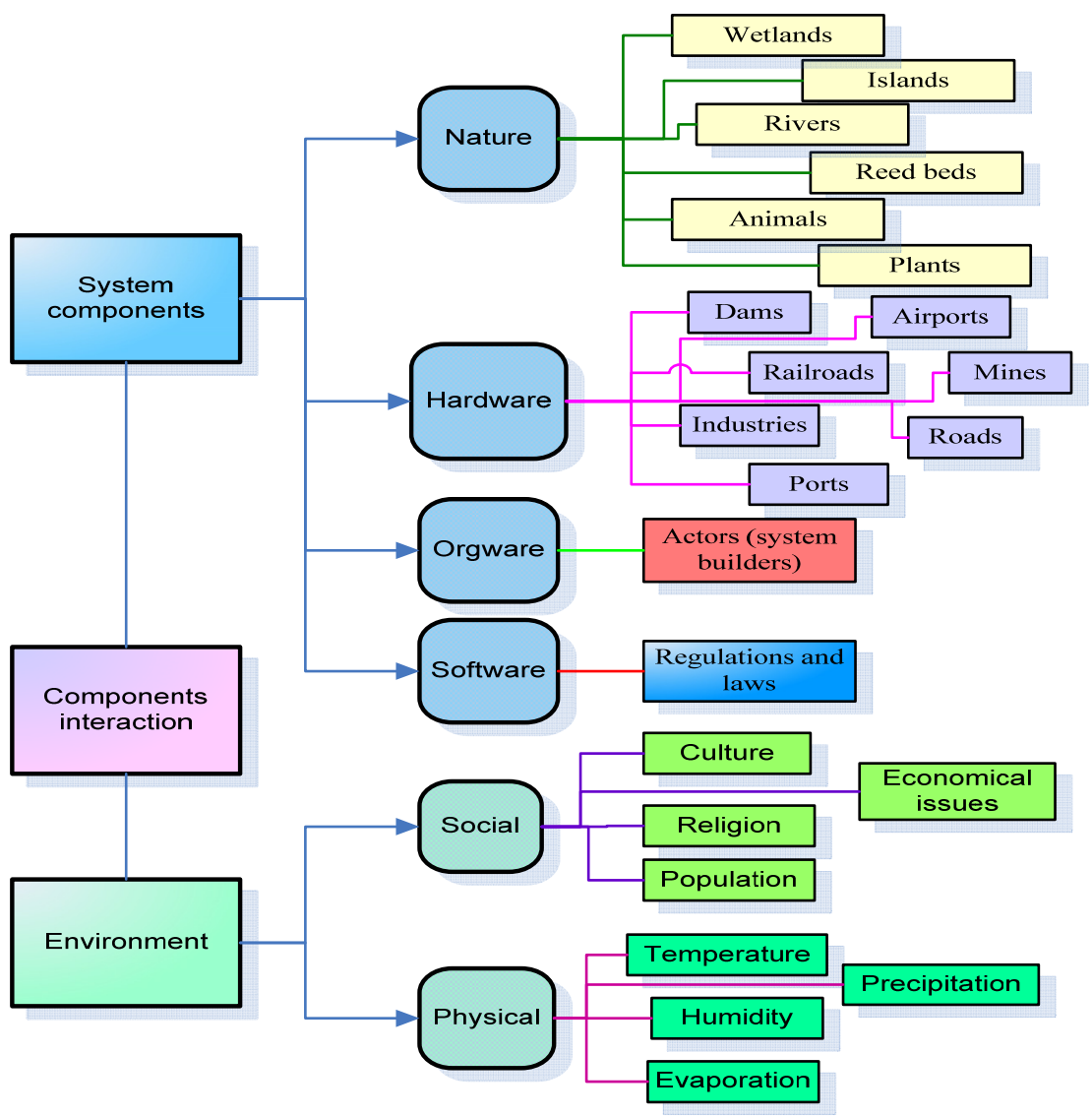

Figure 2: $\quad$ The LTS approach used in the research. 
The economic growth in East and West Azerbaijan improved living conditions of the local population through increasing incomes, a decreasing unemployment rate, and better organized cities and transportation systems. However, it had a negative impact on the ecology, for example, declining wetlands as a result of increasing lands under cultivation. Moreover, the quality of the water has dropped due to the release of wastewater from industries and agriculture into the rivers. Further, the construction of some roads, ports and railroads in the basin can be regarded as a disturbance of the wildlife and natural beauty. There are also some discussions about the effects of a causeway, which divided the lake into a north and south section, on the ecosystem [22].

Some policies in the third development plan were directly related to the management of Lake Urumia. Many researches were performed in this period to assess the ecological conditions of the lake and to enable developing an integrated water management plan for the basin. It should be noticed that drought along with the fall in the lake's water level occurred in this period. Beside many studies and researches, no action was taken to conserve the lake [24]. Finally, the fourth development plan specified explicitly the development and implementation of an ecosystem management plan for Urumia Lake Basin.

The Conservation of Iranian Wetlands Project (CIWP) was the initiative taken to realize the required plan. The project has succeeded to achieve an approved management plan, to get a minimum water requirement of 3.1 billion cubic meters (BCM) for the lake, and to allocate water between the three provinces as well as the lake and its wetlands for normal years [7, 24]. During the case study, there was a negotiation process going on for allocating water during droughts. Furthermore, 24 executive plans were developed, to be realized within five years, to provide water to the lake, additional information to the decision makers, and an appropriate monitoring system. The implementation of these plans has started in 2011-2012 [9]. Besides the executive plans, East and West Azerbaijan have an extra plan for bringing water from other regions. This plan will provide about 0.6 BCM water to West Azerbaijan and 0.3 BCM water to East Azerbaijan [9]. The water will be sent either to the lake or will be directly used in agriculture or industry. Some decision makers disagree with it because of its negative impact on the ecology. Moreover, both provinces have to cancel most of their dam projects since October 2010. The Department of Environment has also prohibited the establishment of any new industry that consumes a lot of water in the basin [9].

\section{The conflicting interests}

A closer look at water supply and water demand in the basin (see Table 1) will help to get a better understanding of the issues. There is no water shortage, comparing demand and supply, for a normal year and there is even some water for further developments. However, some of interviewees mentioned that East Azerbaijan has released about 0.17 BCM water annually to the lake during the last ten years [9]. This indicates that its potential runoff was about $0.95 \mathrm{BCM}$ instead of 1.36 BCM. 
Table 1: $\quad$ An overview of water supply and demand in the basin (BCM) [9].

\begin{tabular}{|c|c|c|c|c|c|}
\hline Province & $\begin{array}{c}\text { Potential } \\
\text { runoff }\end{array}$ & Allocated & $\begin{array}{c}\text { Existing } \\
\text { withdrawal }\end{array}$ & $\begin{array}{c}\text { Send to } \\
\text { the Lake } \\
\text { and } \\
\text { wetlands }\end{array}$ & $\begin{array}{c}\text { Further } \\
\text { development }\end{array}$ \\
\hline $\begin{array}{c}\text { West } \\
\text { Azerbaijan }\end{array}$ & 3.98 & 2.04 & 1.91 & 1.94 & 0.13 \\
\hline $\begin{array}{c}\text { East } \\
\text { Azerbaijan }\end{array}$ & 1.36 & 1.08 & 0.78 & 0.28 & 0.30 \\
\hline Kurdistan & 1.58 & 0.58 & 0.22 & 1.00 & 0.36 \\
\hline Total & 6.92 & 3.70 & 2.91 & 3.22 & 0.79 \\
\hline
\end{tabular}

Moreover, Hashemi [6] points out that the average of the runoff is more likely to be $5 \mathrm{BCM}$ and not $6.9 \mathrm{BCM}$. In this case, if we want to meet the minimum water requirement of the lake, which is $3.2 \mathrm{BCM}$, there will be only $1.8 \mathrm{BCM}$ water left to be allocated between the three provinces. This indicates that the provinces should decrease their water consumption. Therefore, we would like to determine the actions of the stakeholders regarding the implementation of the 24 executive plans to know whether or not they will carry out the plans and release the water towards the lake. So, we will model this situation that existed between August and December 2011 when the data collection and interviews took place.

The 24 executive plans should be implemented by the provincial water boards, the Departments of Environment, and the Department of Jihad-eAgricultures. These plans can be categorized in three groups: 1 . those to inform decision makers and the public, 2. those to reduce demand or to improve supply, and 3. those to manage the water flows into the lake. Ten plans involving the provincial Departments of Environment do not lead to any water saving, but they provide practical information to the decision makers and the possibility of monitoring the quantity and quality of the water flow into the lake. Water saving mainly results from ten executive plans for the provincial water boards. Four plans aim to reduce demand or improve supply. Four plans aim to manage the water flows into the lake. The last two plans aim to provide the decision makers with further information. Most of these plans have an annual budget, but they are included again in the executive plans because they require more budget in order to be implemented in a larger scale [9].

Two of five executive plans involving the provincial Department of Jihad-eAgricultures have a high potential for reducing demand. One of them is a general plan supported by the national government in the whole country and therefore with enough funding. Respondents mentioned that the implementation of the other plan is only possible if it will be implemented at a national level and economic factors will be taken into account as well [9].

The potential water saving from the execution of these plans has been estimated to be 1.8 BCM in the basin. Moreover, there are two other plans with the aim of managing inflows to the lake and finally one plan aims to provide decision makers with further information [9]. As both provinces of East and 
West Azerbaijan have to reduce their consumption and both have the extra option of bringing water from another region, we consider them as one decision maker named Azerbaijan, while Kurdistan is the second decision maker with the opportunity of further development. Table 2 shows the decision makers and their possible actions. The software GMCR II is used for the analysis of this conflict.

Table 2: $\quad$ Decision makers and their possible actions.

\begin{tabular}{|c|c|}
\hline $\begin{array}{l}\text { Decision } \\
\text { makers }\end{array}$ & Options \\
\hline \multirow[t]{2}{*}{ Azerbaijan } & $\begin{array}{l}\text { 1. Reduce: reduce water consumption, manage water } \\
\text { inflow to the lake, and improve the water supply to the } \\
\text { lake within their allocation }\end{array}$ \\
\hline & $\begin{array}{l}\text { 2. Bring: bring water from another region, manage water } \\
\text { inflow to the lake, and improve the water supply to the } \\
\text { lake within their allocation }\end{array}$ \\
\hline \multirow[t]{2}{*}{ Kurdistan } & 3. Release: release the saved water towards the lake \\
\hline & 4. Use: use the saved water for further developments \\
\hline
\end{tabular}

Each of four options in Table 2 can be selected or not, which indicates the possibility of $2^{4}=16$ states. "Mutually Exclusive Options" and "At Least One Option" are applied to generate the feasible states (see Table 3). "Mutually Executive Option" indicates that each decision maker can only choose one option among his/her possible actions, where "At Least One Option" points to it that each decision maker has to choose at least one of his/her options. With these specifications, the final conflict model takes the form of a two-player game, which can be analyzed in a two-by-two table. We continue to use GMCR for illustrative purposes, even if analytically its computing powers were not required for the model shown here. Note that GMCR can handle n-player conflicts with $\mathrm{n}>2$, which are less easy to analyze by hand.

Table 3: $\quad$ Feasible states.

\begin{tabular}{|c|rl|l|l|l|l|}
\hline \multirow{2}{*}{$\begin{array}{c}\text { Decision } \\
\text { makers }\end{array}$} & \multicolumn{2}{|c|}{ Actions } & \multicolumn{4}{|c|}{ Feasible states } \\
\cline { 3 - 7 } & & 1 & 2 & 3 & 4 \\
\hline \multirow{2}{*}{ Azerbaijan } & 1. & Reduce & $\mathrm{Y}$ & $\mathrm{Y}$ & $\mathrm{N}$ & $\mathrm{N}$ \\
\cline { 2 - 7 } & 2. & Bring & $\mathrm{N}$ & $\mathrm{N}$ & $\mathrm{Y}$ & $\mathrm{Y}$ \\
\hline \multirow{2}{*}{ Kurdistan } & 3. & Release & $\mathrm{Y}$ & $\mathrm{N}$ & $\mathrm{Y}$ & $\mathrm{N}$ \\
\cline { 2 - 6 } & 4. & Use & $\mathrm{N}$ & $\mathrm{Y}$ & $\mathrm{N}$ & $\mathrm{Y}$ \\
\hline
\end{tabular}

The interview results show that Kurdistan intends to use the saved water from the implementation of the plans for its further development. They gave two reasons for their intention: their consumption is much less than their water rights and the poor economic part of the province is mainly located in the basin. However, Kurdistan requires a license issued by the Ministry of Energy to 
withdraw its surplus water [9]. Kurdistan would like to contribute in maintaining the lake and thus has participated in the process of developing executive plans. The respondents believe that the province is not affected negatively or positively from Lake Urumia. Kurdistan provides the main part of the water inflow to the lake, while it consumes the agricultural products of West Azerbaijan. Furthermore, there are many people working in the services sector between West Azerbaijan and Kurdistan, which indicates that any negative economic or social loss to West Azerbaijan will negatively influence Kurdistan as well [9].

Azerbaijan has faced difficulties in reducing its water consumption as it has to cut the water allocated to the stakeholders within the province. Therefore, it attempts to improve the water flow into the lake by bringing water from another region and managing the water inflow to the lake, for example, by cloud seeding and preventing illegal water withdrawals. It should be mentioned that both provinces, East and West Azerbaijan, got separate funding for transferring water from another region. Although, releasing water from another region to the lake can have some negative impact on its ecology, the Ministry of Energy has accepted this option because of the lake's value and society's demand for conserving the lake [9]. Table 4 demonstrates the preferences of both decision makers regarding the feasible options.

Table 4: $\quad$ Preferences of decision makers towards the possible outcomes.

\begin{tabular}{|c|c|c|c|c|}
\hline Decision makers & \multicolumn{4}{|c|}{ Feasible states } \\
\hline Kurdistan & 2 & 4 & 1 & 3 \\
\hline Azerbaijan & 3 & 4 & 1 & 2 \\
\hline
\end{tabular}

The equilibrium after running the analysis is state four, which indicates that Kurdistan will use its water saved from the implementation of the plans, while both East and West Azerbaijan will not reduce their consumption and will provide the lake with water by bringing it from another region and managing the water inflow into the lake.

\section{Towards a sustainable water allocation}

The potential runoff in the basin is calculated to be 6.9 BCM in a normal year, while it is estimated that the water use is about 2.91 BCM. The total amount of water allocated to the provinces in a normal year is 3.7 BCM [6]. This indicates that the lake gets its minimum requirement, which is 3.17 BCM. However, it seems that the surface runoff was much less than 6.9 BCM for about ten years as we saw that East Azerbaijan released about 1.7 BCM annually to the lake instead of 2.8 BCM. Considering the current situation of the lake, it can also be concluded that the lake has not received enough water for several years. It has been estimated that a runoff of 5 BCM seems to be more realistic. Considering this amount and using the proportion from allocated water, we see that East and West Azerbaijan consume much more than their allocated share. Kurdistan, 
however, takes a bit less than its water right. The total amount of water that the provinces of East and West Azerbaijan consider to bring from another region is close to their surplus. However, it has been estimated that the water demand will increase to 4.19 BCM in 2021 [7, 27, 28]. So, it is necessary that the provinces take actions towards a more wise use of their water resources.

Action, the 24 executive plans, has been taken recently. The lack of an integrated management plan between the provinces, considering the decline of the lake's water level as an environmental problem and the uncertainty of the available data might be the main reasons for no earlier efforts to maintain the lake. The work done by CIWP indicated that the ecological damage is only one side of the issue. However, the stakeholders still mentioned lack of funding as the main problem for the implementation of the executive plans, while at the same time they were determined to continue their development plans. This may show that they still consider the situation as an environmental problem or that they need further support for finding an appropriate solution for reducing their water consumption.

Let us take one step back to look at the stakeholders' behaviour in two previous cases. Acceptance of an integrated water management plan by the stakeholders was after its being required in the fourth national development plan. The previous attempts for developing such a plan were without success. Financial support by the national government was another motive. Acceptance of the water allocation, however, was related to the initiative by the Department of Environment and CIWP to introduce formal water rights for the lake. This helped to open and carry on negotiations between the Ministry of Energy and the provinces and achieve an agreement. So, it can be expected that giving an economic value to the lake by new regulations will influence the preferences of the decision makers. This can be done by the National Committee, Ministry of Jihad-e-Agriculture or Ministry of Energy. These decision makers can enter the process and add new options to change the preferences of the existing decision makers. For example, the National Committee can use the $50^{\text {th }}$ Principle of the Constitutional Law to directly prohibit economic activities that consume a lot of water, as it did before in Azerbaijan. This principle is: "It shall be considered a public duty in the Islamic Republic to protect the natural environment in which the present as well as future generations shall have a developing social life. Therefore, economic activities or otherwise which cause pollution or an irreparable damage to the environment shall be prohibited" [22].

The Ministry of Energy is the main authority that issues licenses to the provinces to use water resources. This state body is interested in maintaining Lake Urumia and therefore it earlier wanted to block further developments in the basin. So, the ministry can play a major role in the water consumption in the region according to the new situation. Finally, the Ministry of Jihad-eAgriculture also can influence the preferences of her provincial departments as the activities in this sector have a great potential in saving water. Moreover, it was mentioned by the respondents that some executive plans should be developed at the national level in order to be implemented by the farmers. 
Kurdistan is in a different situation as the province has more water rights than its consumption. It is not clear how the province will use its surplus water as they need time for further developments. It might be possible to trade it for modern technologies. Trading water is not common in Iran, but it might be an incentive for Kurdistan to increase its water use more slowly.

\section{Concluding considerations}

The application of the LTS approach has facilitated obtaining the necessary information and structuring it in a systematic way and, consequently, helped providing a clear picture of the region. Using the term "socio-technical network" enhanced the willingness of the respondents to accept the interviews and give information more easily. In addition, the approach has helped to gain better understanding of the decision makers and their interests. So, it can be concluded that the approach has contributed in collecting input for the Graph model for conflict resolution. The approach was helpful in structuring data, but more detailed analysis was needed to understand what the problems were with the water allocation and what conflicting claims existed between the actors.

The usefulness of the Graph model for conflict resolution for this kind of policy questions was verified through the application of the method to previous situations and comparing the results with reality. It has been shown that applying the method may support a negotiation process. This can be done by identifying strategies to change the preferences of decision makers. For example, adding or omitting (a) decision maker(s) or his/their option(s) can change the preferences of one or more decision maker(s).

The combination of the LTS approach and the Graph model for conflict resolution can be used to study disputes among stakeholders in order to reach a resolution or suitable outcome. The drawback of combining these two methods might be that it will take longer to carry out a research compared to using only one of them. In conclusion, the combination is especially appropriate for those cases in which the analyst does not have a clear understanding of the dispute and getting sufficient input information through interviews is hard.

Finally, the interviews have been mostly conducted with governmental respondents who participated in the CIWP. Thus, there might be a bias in the information used in the research. Strategic answering by the respondents may also have negatively influenced the interview results. Furthermore, the validity of the outcomes of the Graph model for conflict resolution is dependent on time. If a new decision maker enters the process or the preferences of at least one of the decision makers change over time, this will result in different outcomes. A more precise plan for influencing the stakeholders' preferences requires further research anyhow.

\section{Acknowledgements}

The paper is based on the TU Delft Management of Technology master thesis of engineer S. Oloumi Zad. We thank the Iranians who gave information or 
otherwise helped during the fieldwork and L. Fang, K. Hipel, M. Kilgour and X. Peng for providing the GMCR II software free of charge.

\section{References}

[1] YEKOM Consulting Engineers, "Managment Plan for the Lake Uromiyeh Ecosystem. 4 Reports,” Tehran, 2002.

[2] YEKOM Consulting Engineers, "Environment Impacts of Uromiyeh Lake's Water Resources Development Projects on the Lake. 9 Reports,” Tehran, 2005.

[3] Pandam Consulting Engineers, "Integrated Water Resources Management for Lake Uromiyeh Basin. 9 Reports,” Tehran, 2005.

[4] Water and Wastewater Macro Planning Bureau, "Upgrading comprehensive water plan of the country in basin Aras, Sefidrud, between Sefidrud and Haraz, Atrak, Uromiyeh. 11 Reports,” Tehran, 2010.

[5] A. Nazaridoust, Methodological Framework, Guidelines and DSS Model to Calculate the Minimal Ecosystem Water Requirements for Wetlands: A Case Study of the International Wetlands in the Lake Urmia Basin. Doctoral Dissertation, Tehran: Azad Islamic University, 2006.

[6] M. Hashemi, A socio-technical assessment framework for integrated water resources management (IWRM) in lake URmia Basin, Iran, dissertation, 2012.

[7] UNDP/GEF/DOE Conservation of Iranian Wetlands Project, Integrated management plan for lake Uromiyeh, 2008.

[8] UNDP/GEF/DOE Conservation of Iranian Wetlands Project, Integrated management plan for Lake Urumia Basin:approved version, 2010.

[9] S. Oloumi Zad, Managing conflicts in water resources allocation: a sustainable water allocation for Urumia Lake Basin in Iran, Thesis, Delft: Delft University of Technology Institutional Repository, 2012.

[10] W. Ravesteijn, L. Hermans and E. van der Vleuten, "Participation and globalization in water system building,” Knowledge, Technology \& Policy, vol. 14, no. 4, pp. 4-12, 2002.

[11] T. Hughes, Networks of power: Electrification in Western society 18801930, Baktimore: The Johns Hopkins University Press, 1983.

[12] T. Hughes, “The Evolution of Large Technological Systems,” in The social construction of technological systems, First edition ed., Cambridge, Massachusetts; London, The MIT Press, 1989, pp. 51-82.

[13] E. van der Vleuten, "Large Technical Systems," in A Companion to the Philosophy of Technology, Blackwell Publishing Ltd, 2009, pp. 218-222.

[14] B. Joerges, "Large Technical Systems: Concepts and Issues," in The Development of Large Technical Systems, Westview Press, 1988, pp. 9-36.

[15] M. Kilgour and K. Hipel, Conflict analysis methods: the graph model for conflict resolution, Springer, 2010.

[16] N. Howard, Paradoxes of rationality: theory of metagames and political behavior, The MIT press, 1971. 
[17] L. Fang, K. Hipel and D. Kilgour, Interactive decision making-the graph model for conflict resolution, Wiley, 1993.

[18] N. Fraser and W. Hipel, Conflict analysis models and resolutions, Elsevier Science Publishing Co.,Inc., 1984.

[19] K. Hipel, M. Kilgour and L. Fang, The graph model for conflict resolution, Encyclopedia of life support systems, 1993.

[20] YEKOM Consulting Engineers1, "Management Plan for the Lake Uromiyeh Ecosystem, Report 1 of the EC-IIP Environmental Management Project for Lake Uromiyeh, 11 chapters.,” Tehran, 2002.

[21] YEKOM Consulting Engineers3, "Review of the capacity to manage the lake Uromiyeh ecosystem. Report 3 of the EC-IIP Environment Management Project for Lake Urumiyeh. 4 chapters,” 2002.

[22] YEKOM Consulting Engineers2, "Human activities and their impacts on the lake Uromiyeh ecosystem, Report 2 of teh EC-IIP Environmental Management Project for Lake Uromiyeh, 9 chapters,” 2002.

[23] M. Hashemi, "The status of water resources in the Lake Uromiyeh Basin," 2008.

[24] YEKOM Consulting Engineers9, "Environment impacts of Urumia Lake's water resource development projects on the lake- the comprehensive plan," Tehran, 2005.

[25] Pandam Consulting Engineers2, "Integrated Water Resources Management for Lake Urommiyeh Basin, Module 3: water for ecosystems,” 2005.

[26] Pandam Consulting Engineers1, "Integrated water resources management for the Lake Uromiyeh Basin, Module 3: water for ecosystems,” 2005. 